\title{
La transición a la cultura universitaria en la interpretación y las vivencias de estudiantes de Ciencias de la Educación
}

\author{
The transition to university culture in the interpretation and \\ experiences of students of Educational Sciences
}

\author{
Lic. Lisel I. Silvestri ${ }^{1}$
}

Fecha de recepción: 07/05/2012

Fecha de aceptación y versión final: 11/10/12

Resumen: Este trabajo informa resultados de una investigación dedicada a examinar la perspectiva de estudiantes de Ciencias de la Educación con un año de permanencia en la carrera, sobre cuestiones relacionadas con la transición del nivel medio a la universidad. Centramos el análisis en sus apreciaciones acerca de las modificaciones en la frecuencia de uso de las estrategias empleadas en la universidad y en la escuela, las dificultades en la vida académica y las condiciones de estudio y aprendizaje en cada contexto. Treinta y cuatro estudiantes respondieron un cuestionario estructurado, y quince de ellos participaron en entrevistas. Los procesos de autorregulación revelan una importancia decisiva, tanto por tratarse de las estrategias mayormente desarrolladas en la facultad, como por constituir lo propio del estudio en el nivel superior, especialmente en cuanto al logro de autonomía, la organización del tiempo y la regulación del esfuerzo. Consistentemente, las principales dificultades corresponden a la ausencia de un hábito de estudio ajustado a las nuevas exigencias, lo cual compromete el desempeño académico en la asistencia a clases, la lectura de textos, la constancia, el tiempo de estudio y la preparación de exámenes. La experiencia adquirida durante el tiempo de afiliación y aprendizaje que supone el primer año, ha posibilitado una amplia comprensión de aquello que es indispensable asumir y comprometer en la actuación académica para aspirar a la permanencia exitosa en el sistema de educación superior, lo cual no implica necesariamente que en la práctica los estudiantes pueda actuar conforme a esa comprensión de modo sostenido.

Palabras clave: estudiante de profesorado, transición, universidad, estrategias de aprendizaje, autorregulación.

Abstract: This paper reports results of a research intended to examine the perspective of students of educational sciences with in their first year in the course of studies, about issues related to the transition from secondary school to university. We focus on the analysis on their appreciations about the changes in the frecuency of use of the strategies employed at secondary school and at university, the difficulties in academic life and the conditions of study and learning in each context. Thirty four students answered a structured questionnaire, and fifteen of them participated in interviews. The self-regulation processes bears a decisive importance, mainly due to the fact they are the learning strategies most used in their course of studies as well as because they are specific of university studies, in particular as regards as autonomy achievement, the organization of time and effort regulation. Consistently, the main difficulties refers to the absence of a study habit adjusted to new demands, which compromises academic performance in the class attendance, reading literature, perseverance, time devoted study and the exams preparation. The experience gained during the time of affiliation and learning in the first year, has provided them with a broad understanding of what is essential to adopt and what needs to be involved in academic performance to aspire to be successful in higher education, which does not necessarily imply in practice that students may act in accordance with that understanding in a sustained way.

Key words: student teachers, transition, university, learning strategies, self-regulation.

\footnotetext{
${ }^{1}$ Facultad de Humanidades - UNNE - correo electrónico: lisel.silvestri@yahoo.com.ar
} 


\section{Introducción}

El propósito de este artículo es examinar algunas dimensiones relevantes en la transición de la escuela media a la cultura universitaria, desde las interpretaciones y vivencias de estudiantes de Ciencias de la educación al cabo de un año de permanencia en la carrera. Específicamente, nos interesa caracterizar su perspectiva en relación con: a) las modificaciones y/o cambios en la frecuencia de uso de las estrategias de aprendizaje empleadas durante el nivel medio y en la universidad, b) las principales dificultades y carencias durante el primer año, y c) la particularidad de ambos contextos en lo referido a las condiciones en que se estudia y aprende.

El desafío de iniciar una carrera de grado y adentrarse paulatinamente en la dinámica universitaria plantea al estudiante la posibilidad de acceder a una nueva realidad vital e institucional, y por ello lo compromete fuertemente tanto desde el punto de vista personal como académico. Desde su llegada a la universidad, se ve en la imperiosa necesidad de familiarizarse con nuevos lenguajes y normas institucionales, incorporar conocimientos de mayor complejidad y especificidad que los adquiridos precedentemente, adaptarse a nuevos estilos docentes y a diferentes modalidades de evaluación, manejar un mayor volumen de bibliografía, y en especial, conquistar una autorregulación del tiempo y el esfuerzo a la que puede no estar acostumbrado al finalizar el nivel medio. Además, las valoraciones y significados que los alumnos construyen en torno al estudio universitario, se relacionan con su historia de vida y sus trayectorias escolares previas. De allí la importancia de estimularlos a evocar sus experiencias durante el nivel medio.

La ambientación de los estudiantes durante el primer año de la educación superior se relaciona estrechamente con lo que Perrenoud (1996), refiriendo a otros niveles del sistema, ha caracterizado como el aprendizaje del oficio de alumno. Según el autor, éste supone tanto la aprehensión de los contenidos de conocimiento y de los procesos que la posibilitan, como la internalización de las reglas del juego propias de la institución. Para aprender este oficio, el estudiante debe lograr el dominio de los instrumentos que el mismo requiere y conocer las reglas que regulan su ejercicio. En tal sentido, el acceso y especialmente la permanencia en el nuevo nivel exige incorporar: "los saberes y el saber hacer, valores y códigos, costumbres y actitudes, que convertirán al alumno en el perfecto 'indígena' de la institución” (1996:217-8). Si esta adquisición no resulta plena, deberá desarrollar, al menos, aquellas competencias: "que le permitirán sobrevivir sin demasiadas frustraciones gracias a haber comprendido las maneras que se consideran adecuadas" (p. 218).

En este contexto, la vida del estudiante de educación superior exige un proceso de resocialización respecto de las competencias previamente adquiridas en la escuela. Se trata de un cambio de actitudes, necesariamente gradual, que involucra tanto el ámbito de lo cognitivo, como también de lo afectivo y lo volitivo (C. de Zurita, 1996).

Según Teobaldo y Melgar (2009), ser alumno de una nueva institución correspondiente a un nivel superior del que se procede, significa enfrentar la complejidad inherente a todo pasaje de un nivel a otro del sistema, tanto en lo relativo a las peculiaridades de la estructura del nuevo nivel como en aquellas que conciernen a la unidad educativa específica a la que se ingresa. Es entonces un volver a nacer en relación con la propuesta curricular que encuentra el alumno, las políticas académicas y estilos de gestión institucional predominantes, los procedimientos administrativos, la formación académica de los docentes, la especificidad de los procesos de enseñanza y aprendizaje, las características de la bibliografía, el diferente manejo del tiempo. 
Leite (2003), sintetiza lo expuesto al afirmar que el aprendizaje en la universidad supone ante todo, un aprender a ser estudiante e ir conformando una identidad singular al interiorizar un conjunto de reglas, normas y pautas generalmente tácitas pero imprescindibles para sobrevivir allí.

Los jóvenes comienzan sus estudios de grado provistos de un conjunto de hábitos de estudio adquiridos a lo largo de su escolaridad previa que, por lo general, se caracterizan por ser diferentes a las prácticas esperadas y promovidas por el entorno académico. Dadas estas condiciones les es vital captar la lógica de la organización institucional universitaria así como también, los modos mejor adecuados para interpretar y resolver las exigencias del estudio. Se espera además que el estudiante universitario asuma el continuo ejercicio de la responsabilidad y un uso más individualizado del tiempo dedicado al estudio, lo cual deriva de una mayor autonomía en las decisiones, al tiempo que la posibilita.

Desde el análisis del investigador Alain Coulon (1995), puede concebirse el ingreso a la vida universitaria como el tránsito o pasaje de un estatus social a otro, de un entorno cultural a otro. Un marco de referencia interesante para pensar la complejidad de los problemas que deben afrontar los estudiantes en su inserción al ámbito académico, corresponde a las tres dimensiones temporales que identifica y caracteriza el autor:

- tiempo del extrañamiento; la llegada a la universidad representa una serie de fuertes rupturas. El joven estudiante abandona sus antiguas referencias $u$ orientaciones y se enfrenta a un universo institucional desconocido, cuyas pautas rompen el mundo que acaba de dejar y que le resulta ciertamente familiar. Predominan algunos mitos que no se corresponden con las prácticas, costumbres y reglas del nuevo lugar, por lo que puede experimentar un sentimiento de aislamiento, de soledad e incluso de anomia. En este primer contacto siente miedo y emoción a la vez, pero no lo vivencia de forma totalmente negativa, pues prevalece el sentimiento de superar una etapa crucial.

- tiempo del aprendizaje; en el curso de este período de incertidumbres el estudiante se adapta progresivamente a las nuevas reglas institucionales. Involucrado en un proceso de resocialización en las normas del nuevo nivel y de la institución social específica de la cual empieza a formar parte, debe transformar pautas de acción, creencias y actitudes. Los aprendizajes complejos deben operarse rápidamente, como aquel de organizar autónomamente el trabajo personal. De novato, el estudiante se convierte en aprendiz, moviliza sus energías para conformar su nuevo oficio de universitario y las rutinas se instalan (define estrategias para avanzar en los cursos, para superar el anonimato, para determinar las tareas que debe cumplir de forma urgente y eficaz para cada materia, etc.) Este tiempo puede extenderse a lo largo de todo el primer año de estudio o más, y se va resolviendo a medida que se presentan experiencias de participación diferentes a las ya conocidas.

- tiempo de la afiliación; este proceso se entiende como la progresiva adquisición de un nuevo status. El estudiante se vuelve a encontrar, adquiere el dominio de las reglas de la universidad, de su lenguaje y sus exigencias. Vive el sentimiento de haber sorteado las dificultades más importantes y logra convertirse en un miembro de la comunidad universitaria. La afiliación se manifiesta principalmente en su capacidad para interpretar los significados institucionales, lo que le permite tanto ajustarse a las normas como transgredirlas, sin comprometer su permanencia en la institución. 
Ciertamente, la universidad constituye para el estudiante ingresante ese universo institucional desconocido al que alude Coulon. El transcurrir del primer año académico, momento en que se produce la transición escuela media / universidad, es el tiempo del extrañamiento y del aprendizaje de nuevas pautas y reglas del juego, en especial aquellas referidas al dominio de los saberes y a sus lenguajes propios, a las formas de adquisición de esos saberes y a la relación que se construye con el conocimiento.

Asimismo, el pasaje al ámbito universitario exige a los alumnos un considerable esfuerzo adaptativo pudiendo presumirse que al cabo de un año de permanencia en él, la mayoría se ha ambientado en cierta medida a la nueva modalidad en sus múltiples dimensiones. En suma, aprender las reglas universitarias significa para los estudiantes desplegar estrategias de aprendizaje caracterizadas por un mayor grado de autonomía del que los habituó el secundario, autonomía que implica poner en juego procesos de autorregulación que optimicen el proceso y condiciones que lo estimulen a adquirir competencias más acordes a los requerimientos del estudio universitario.

De modo global, se entiende a las estrategias como actividades $u$ operaciones mentales dirigidas a facilitar y optimizar el aprendizaje. Entre los autores más representativos del campo existe un amplio consenso en cuanto a destacar ciertos elementos substanciales del concepto: por un lado, las estrategias implican una secuencia de actividades, operaciones o planes dirigidos a la consecución de metas de aprendizaje; y por otro, tienen un carácter consciente e intencional que supone por parte del alumno procesos de toma de decisiones ajustados al objetivo (Valle, Barca, González y Núñez, 1999). Un estudiante utiliza una estrategia cuando logra ajustar su comportamiento a las exigencias de una tarea o actividad requerida por el profesor, y a las circunstancias y vicisitudes en que se produce la demanda (Monereo, 2006). En un sentido general, consisten en la toma de decisiones en condiciones específicas, y más concretamente se define a las estrategias como: "procesos de toma de decisiones (conscientes e intencionales) en los cuales el alumno elige y recupera, de manera coordinada, los conocimientos que necesita para cumplimentar una determinada demanda u objetivo, dependiendo de las características de la situación educativa en que se produce la acción" (2006:27).

En cuanto a los diferentes tipos de estrategias, Valle Arias y otros advierten que pese a la amplia variedad de aportes al momento de clasificarlas, se observan ciertas coincidencias en la definición de tres grandes categorías: las estrategias cognitivas, metacognitivas o de control de la comprensión y las de autorregulación, también denominadas estrategias de manejo de recursos.

Con relación al primer grupo, asumimos como marco categorial la clásica propuesta de Weinstein y Mayer (1983), quienes distinguen tres tipos de estrategias cognitivas: estrategias de ensayo, de elaboración y organización. Más tarde, dicha perspectiva fue complementada por la propia Weinstein (1988, en Gargallo, 1995), recogiendo las estrategias ordenadas desde un nivel de procesamiento más superficial a más profundo o complejo y desde el menor control cognitivo exigido al mayor, incluyendo:

- Estrategias de ensayo o repetición; para tareas básicas de aprendizaje requieren el simple recuerdo (cuyo ejemplo más representativo sería la pura repetición ordenada) o para tareas complejas de aprendizaje que exigen ir más allá del aprendizaje superficial de listas o bloques inconexos de información (por ej., el subrayado o la copia literal).

- Estrategias de elaboración; para tareas básicas de aprendizaje donde la elaboración implica algún tipo de construcción simbólica de lo que se quiere aprender para hacerlo más inteligible (como las imágenes mentales o las palabras clave) o para tareas complejas que buscan establecer puentes entre 
lo que ya se sabe y lo nuevo (ejemplos de este tipo de estrategias son las analogías o el parafraseado).

- Estrategias de organización; para tareas básicas de aprendizaje dirigidas a reestructurar la información para hacerla más fácilmente inteligible (el agrupamiento en categorías o la taxonomización que permiten dar una nueva estructura a la información) o para tareas complejas (tales como la identificación de la estructura de un texto, los diagramas de causa-efecto o las jerarquías conceptuales).

De acuerdo con Beltrán (1998), la repetición es un mecanismo de la memoria que activa los datos informativos para mantenerlos en la memoria a corto plazo y, a la vez, facilitar su transferencia a la memoria a largo plazo y su posterior recuperación. Por otra parte, la estrategia de elaboración realiza conexiones externas para integrar los materiales informativos relacionando la nueva información con la ya disponible en la memoria; mientras que la estrategia de organización establece conexiones internas entre los datos para combinar los elementos informativos seleccionados en un todo coherente y significativo. Pozo (1990) afirma que las estrategias de repetición se relacionan con un aprendizaje asociativo y con un enfoque superficial del aprendizaje, en cambio, las estrategias de elaboración y organización estarían vinculadas a un tipo de aprendizaje por reestructuración y a un enfoque profundo de aprendizaje.

Según González y Tourón (1992), mientras que las estrategias cognitivas tratan de integrar el nuevo material con los conocimientos previos; las metacognitivas se ocupan de la planificación, control y evaluación de la propia cognición. Las primeras se desarrollan para aprender, codificar, comprender y recordar la información con vista al logro de determinadas metas de aprendizaje; en tanto las últimas posibilitan el conocimiento, control y regulación de los procesos mentales.

Por último, en opinión de estos autores, las estrategias de autorregulación constituyen una serie de estrategias de apoyo al aprendizaje e involucran diferentes tipos de recursos que contribuyen a que la resolución de una tarea resulte satisfactoria. Gran parte de estas estrategias se relacionan con la disposición afectiva y motivacional hacia el aprendizaje. Precisamente, la investigación en el área se ha centrado en las estrategias que emplean los estudiantes para enfocar la atención, mantener la concentración, manejar la ansiedad, establecer y mantener la motivación y gestionar eficazmente su tiempo (Weinstein y Mayer, 1983).

\section{Diseño de la Investigación}

Se recurrió a una estrategia propia del campo de la investigación en Psicología Educativa, consistente en la selección de varios casos para ser estudiados con detenimiento y en torno a una temática específica, cuyos sub temas o contenidos se encuentran ya identificados. Cada caso interesa tanto por lo que tiene de único como por lo que comparte con otros casos similares, a través de ellos se accede al estudio de la particularidad y complejidad de casos singulares, para llegar a comprender las pautas de su actividad en el contexto académico. El conocimiento de casos, suficientemente diversificados, permitió caracterizar la perspectiva de los estudiantes de Ciencias de la Educación sobre la transición del nivel medio a la universidad. 


\section{Universo y muestra}

Participaron los estudiantes del profesorado en Ciencias de la Educación de la Facultad de Humanidades de la UNNE, con un año de permanencia en la carrera.

Se seleccionaron dos muestras intencionales. En una primera instancia, incluyó treinta y cuatro estudiantes que respondieron un cuestionario estructurado. En un segundo momento, se definió una submuestra de quince alumnos para la realización de entrevistas en profundidad.

Conjuntamente con la permanencia en la carrera al cabo de un año del ingreso, la selección de los participantes consideró la accesibilidad como criterio pragmático complementario para asegurar la mejor disponibilidad del estudiante al momento de proveer la información. Éste respondió a la necesidad de contar con el consentimiento y compromiso de los estudiantes, en virtud del carácter voluntario de su participación.

Para la selección de los sujetos en la muestra menor, se tuvo en cuenta la variabilidad en el rendimiento académico, factor de cierto peso que consideramos podría operar como indicador de algunas diferencias importantes en torno a las cuestiones examinadas mediante las entrevistas. Con la intención de que el rendimiento estuviese representado en sus distintos niveles, se escogieron cinco estudiantes para cada categoría de rendimiento: alto, medio y bajo. La categorización se realizó conforme a la construcción de un índice que combinó el promedio histórico (materias aprobadas y desaprobadas), el número de materias regularizadas y las calificaciones obtenidas, con relación a lo establecido en el plan de estudio de la carrera.

\section{Técnicas}

El diseño combinó los siguientes procedimientos en relación de complementariedad:

a) Cuestionario estructurado; conformado por ítems precategorizados para examinar las percepciones y valoraciones de los estudiantes en relación con las estrategias de aprendizaje utilizadas durante la escuela secundaria y en la universidad, así como las condiciones de estudio propias del nivel superior. Incluyó además un planteamiento de respuesta abierta que, apelando a la experiencia adquirida durante el primer año, recogió sus apreciaciones sobre las principales dificultades para estudiar y aprender en el ámbito académico. El diseño del instrumento distinguió dos apartados temáticos: 'Las Estrategias en el Nivel Medio y en la Universidad' y 'El estudio en la Universidad', cada uno de los cuales comprendió distintas dimensiones. Para el primer apartado se presentaron en paralelo veintiún ítems relativos a las dimensiones cognitiva, metacognitiva y de autorregulación de las estrategias de aprendizaje, dispuestos en un cuadro comparativo: Nivel Medio / Universidad. Se solicitó señalar la frecuencia de uso de ciertas estrategias para ambos contextos, teniendo en cuenta una escala de tres valores: frecuentemente/ a veces/ casi nunca. Para el segundo apartado, se plantearon cuarenta afirmaciones referidas al modo de estudiar y aprender en la universidad y a posibles dificultades en la vida académica. Se utilizó la misma escala de tres valores, pero en esta ocasión las instrucciones solicitaron seleccionar la opción que representara mejor la frecuencia de ocurrencia de las situaciones planteadas. Las afirmaciones ofrecidas atendieron a cuestiones como la atención y concentración en el estudio, la dedicación y la organización del tiempo, la asistencia a clases, el registro de apuntes, la bibliografía, el trabajo grupal, la situación de examen, entre otras. 
La información provista por el cuestionario contribuyó al mejor ajuste del contenido del segundo procedimiento empleado:

b) Entrevistas en profundidad; se orientaron a recuperar e informar la experiencia de los estudiantes sobre asuntos vinculados con las dificultades durante el primer año académico y las particularidades del estudio en la escuela y en la universidad. Fueron realizadas a quince estudiantes con diferente nivel de rendimiento, seleccionados entre quienes respondieron el cuestionario. Se expresaron espontáneamente en torno a un amplio conjunto de tópicos que funcionaron a modo de disparadores: autonomía, autorregulación del tiempo y el esfuerzo, relaciones interpersonales, lectura, modo de estudiar, asistencia a clases, material de estudio, etcétera. Las entrevistas posibilitaron retornar con mayor profundidad sobre algunos de los aspectos examinados mediante el cuestionario, y si bien no fue requerido, muchos estudiantes construyeron sus respuestas en términos comparativos con sus experiencias en el nivel medio.

\section{Procedimiento y análisis de datos}

El cuestionario fue respondido en forma autoadministrada por estudiantes que iniciaban el cursado de una materia cuatrimestral correspondiente al segundo nivel de la carrera y que, en comparación con otras cátedras masivas del mismo nivel, no contaba con un número de alumnos muy numeroso. Cabe destacar, que el hecho de que al momento de recoger los datos se encontraran cursando el segundo nivel del profesorado, no necesariamente implica que el estudiante hubiera cumplimentado en forma completa los requerimientos académicos del primer nivel. Las entrevistas fueron realizadas en forma individual, acordando con los estudiantes un espacio y tiempo.

El tratamiento de los datos provistos por el cuestionario consistió fundamentalmente en un procesamiento cuantitativo. Con los señalamientos, en respuesta a las preguntas precategorizadas, se realizó un análisis de distribución de frecuencias, centrado en la alternativa seleccionada para cada planteamiento. Para el análisis de la pregunta de respuesta abierta, se efectuó un agrupamiento y posterior categorización de los aspectos comunes planteados en las respuestas libres de los alumnos.

La información recogida durante las entrevistas fue procesada mediante un análisis de contenido de los comentarios y expresiones de los alumnos, con el objeto de construir una categorización de cuestiones comunes y divergentes entre las perspectivas asumidas por cada uno de ellos frente a los diferentes tópicos.

\section{Resultados}

\section{A) Utilización de estrategias en la transición del nivel medio a la universidad.}

Se presentó en paralelo el mismo conjunto de estrategias de aprendizaje: cognitivas, metacognitivas y de autorregulación, para que el estudiante indicara su frecuencia de uso en la escuela media y en la universidad.

\section{Estrategias cognitivas de repaso, elaboración y organización}

De acuerdo con Pozo (1990), la estrategia asociativa más estudiada es el repaso, consistente en recitar o nombrar repetidamente los ítems o estímulos presentados en una tarea de aprendizaje durante la fase de adquisición. Dentro de este grupo de estrategias de ensayo para tareas complejas de aprendizaje, Weinstein y Mayer (1983), incluyen también actividades como la copia o repaso escrito y el subrayado. Al 
igual que el repaso, éstas tratan de influir en la atención y en el proceso de codificación en la memoria de trabajo, facilitando un nivel de comprensión superficial.

A este respecto, hallamos que repetir el contenido en voz alta no muestra variaciones en cuanto a su utilización en la escuela media y en la universidad. Sin embargo, no ocurre lo mismo con subrayar y copiar o tomar notas literales, mientras que más de dos tercios de los treinta y cuatro alumnos encuestados indican su uso habitual para las tareas académicas, una proporción casi equivalente informa la escasa o esporádica aplicación de estas habilidades en el contexto escolar.

Con relación a las estrategias de elaboración, Pozo afirma que buscan una relación, un referente o significado común a los ítems que deben aprenderse. Entre las estrategias de elaboración para tareas complejas de aprendizaje, Weinstein y Mayer señalan el parafraseo, el resumen y la descripción de cómo se relaciona la nueva información con los conocimientos previos. Mencionan también en este grupo, crear analogías, tomar notas personalizadas y responder preguntas. Por su parte, al examinar la distinción entre estrategias de elaboración simple y de elaboración compleja, Pozo explica que las primeras facilitan el aprendizaje de un material escasa o nulamente estructurado mediante el recurso a una estructura externa a la que se asocia ese material, y que actúa en paralelo sin llegar a impregnarlo de su significado. Incluye aquí las palabras clave, imágenes mentales, rimas, abreviaturas y frases, y utilización de códigos. En cambio, en las de elaboración compleja, la estructura externa pasa a ser asumida al menos en parte, por el propio material de aprendizaje (es el caso del uso de analogías y del conjunto de técnicas que emplea el lector para elaborar un texto escrito: por ej. elaborar resúmenes, formular preguntas, comparar).

El análisis de las selecciones evidencia que sólo el resumen revela la misma regularidad de uso para ambos niveles de formación. Tanto tomar apuntes personalizados como realizar notas marginales son señalados como recursos aprovechados con menor frecuencia en el secundario. De igual modo, más de dos tercios de los alumnos indican para la universidad una utilización frecuente de sintetizar textos de forma personal, establecer relaciones entre diferentes autores $e$ ideas y relacionar los nuevos contenidos con los conocimientos previos. Aproximadamente la misma proporción asegura emplear también asiduamente, las estrategias de ejemplificar y estudiar o resumir textos con las propias palabras.

Finalmente, las estrategias de organización permiten establecer explícitamente las interrelaciones entre los elementos que conforman el material de aprendizaje. Constituyen la forma más sofisticada de aprenderlo y exigen implicación activa y un mayor esfuerzo del sujeto (Pozo, 1990). Según Weinstein y Mayer, sus objetivos corresponden a la selección de información para ser transferida a la memoria de trabajo y la construcción de relaciones entre las ideas allí disponibles. La identificación de estructuras textuales, la clasificación ordenada de elementos, la creación de jerarquías, la esquematización de textos y la construcción de representaciones gráficas son las estrategias mencionadas por estos autores.

Los estudiantes reconocen un mayor desarrollo de estas estrategias en el ámbito académico, en comparación con su uso en el nivel medio. Identificar ideas centrales y secundarias es señalada como una técnica de uso regular por la mayoría, en tanto que una cantidad algo menor manifiesta representar gráficamente con la misma asiduidad. Poco menos de la mitad señala establecer semejanzas/diferencias $y$ ventajas/desventajas al interior del texto como una de sus estrategias habituales en la facultad, y una proporción similar indica su uso ocasional. 


\section{Estrategias metacognitivas o de control de la comprensión}

Para Gargallo (1995), de modo general la metacognición refiere al conocimiento y regulación de nuestros procesos y productos cognitivos o cualquier otro asunto relacionado con ellos, por ejemplo las propiedades de la información relevante para el aprendizaje. Comporta el establecimiento de metas, la evaluación del grado de logro de las mismas y la modificación de las estrategias empleadas cuando no son pertinentes, por consiguiente exigen un grado de control cognitivo muy elevado.

Conforme los señalamientos de nuestros estudiantes, estas estrategias se ponen mayormente en juego durante el primer año universitario. No obstante, se observan diferencias en la frecuencia de uso señalada para las distintas alternativas ofrecidas. Casi el total de los alumnos encuestados manifiesta realizar habitualmente una relectura con pausas para reflexionar sobre lo leído. Una proporción algo menor acepta que a medida que lee textos académicos se plantea preguntas e intenta responderlas. En cambio, pocos entre ellos reconocen el uso de dichas estrategias para regular la actividad lectora en el nivel medio. En cuanto a la estrategia revisar el modo de estudiar para valorar su eficacia, al igual que autoevaluarse periódicamente teniendo en cuenta objetivos propuestos y resultados obtenidos, hallamos que los alumnos las consideran de escasa aplicación tanto en la escuela como en la facultad.

\section{Estrategias de autorregulación, de apoyo o manejo de recursos}

Estas estrategias se orientan a crear el mejor ambiente o clima posible, las óptimas condiciones y el mejor apoyo a las estrategias primarias (cognición y metacognición). Tal como sostiene Pozo (1990), en lugar de enfocarse directamente sobre el proceso de aprendizaje, se orientarían a la mejora de las condiciones materiales y psicológicas en las que éste se desarrolla. Lograr la autorregulación pareciera ser lo propio del estudio universitario en la valoración de estos estudiantes.

Para la totalidad de las estrategias planteadas, más de dos tercios de los estudiantes indican una utilización frecuente, en tanto el resto las pone en juego ocasionalmente. Como contrapartida, en la escuela apenas un tercio señala haber utilizado frecuentemente estrategias como planificar las actividades en pasos 0 instancias sucesivas, advertir el esfuerzo y los recursos que puede demandar una determinada tarea y conseguir a tiempo los recursos necesarios para cumplimentarla. Algo similar ocurre con prever y organizar adecuadamente el tiempo de estudio, estrategia que la mayoría señala no haber considerado casi nunca o sólo a veces en el nivel medio.

\section{B) Dificultades y carencias más importantes durante el primer año académico.}

Una lectura del conjunto de las apreciaciones ofrecidas por los estudiantes destaca que las principales dificultades en el curso del primer año universitario, refieren fundamentalmente al logro de una adecuada autorregulación de la conducta para el estudio, y a la insuficiencia de los contenidos adquiridos en el nivel medio. En menor medida, estos alumnos apelan a factores externos sobre las cuales puede ejercer menos control y en consecuencia, menos ajustes y cambios.

Aún cuando perciben los ajustes que el nuevo contexto institucional les demanda, en la mayoría de los casos persisten las prácticas de estudio desarrolladas en la escuela secundaria, lo cual periódicamente los enfrenta a inconvenientes de diversa 
índole. Entre los diversos problemas que comparten los estudiantes de forma recurrente, pueden mencionarse los siguientes:

- Ser autónomo y responsable; la independencia en la conducción del estudio aparece como un aspecto clave que condiciona ampliamente su desenvolvimiento en el nivel superior.

- Gestionar el tiempo convenientemente y sostener el esfuerzo: en la mayoría de los casos reconocen no haber consolidado un habito de estudio en su paso por la escuela, por lo que aún en la universidad su nivel de compromiso aumenta cuanto más escaso es el tiempo del que disponen para la realización de los trabajos o para la preparación de exámenes. Estas dificultades se tornan palpables en situaciones como estudiar simultáneamente diferentes materias en un período de tiempo escaso; organizar deficientemente el tiempo destinado al cumplimiento de las actividades académicas; improvisar la realización de las tareas y trabajos prácticos como consecuencia de no cumplimentar lo planificado; y elaborar los trabajos a última hora por postergarlos más de lo recomendable.

- Regular adecuadamente el tiempo dedicado a la lectura y al seguimiento de los textos: prácticamente todos los alumnos encuestados usualmente o a veces, únicamente lee los textos obligatorios que los profesores destacan como tema de examen. De modo consistente, la consulta de bibliografía complementaria queda relegada a la realización de trabajos prácticos, y la búsqueda de material o información adicional no pedida por el docente, es una iniciativa ocasional de sólo unos pocos para ciertas producciones. Además, con frecuencia u ocasionalmente la mayoría asiste a clases sin la lectura de los textos solicitados. Frente a este escenario, podría pensarse la lectura de estos alumnos en términos de una práctica más bien formalizada, pues en mayor medida se realiza respondiendo a requerimientos puntuales de los profesores y limitándose a aquellos contenidos que transmite y, de algún modo, legitima la institución.

- Adecuarse a la dinámica grupal: entablar nuevas relaciones, y conformar un equipo de trabajo estable y funcional. Relacionarse y aprender a trabajar con otros es percibido por la mayoría como una necesidad que si bien plantea dificultades, amplía o restringe sus posibilidades de una plena incorporación a la vida universitaria.

- Dificultades de índole cognitiva; su presencia en las explicaciones de los estudiantes es bastante menor en comparación con el peso concedido a la autorregulación. Refiriendo a sus experiencias en el nivel medio, mencionan carencias relativas a la adquisición insuficiente o deficiente de ciertos contenidos disciplinares vinculados con la carrera escogida. Asimismo, destacan la escasa utilización de técnicas y estrategias de aprendizaje que en la universidad se revelan como indispensables al momento de estudiar. Este tipo de problemas se hallan asociados con las características del material de estudio en la facultad, el cual no sólo es notoriamente mucho más extenso, sino que también reviste mayor complejidad y especificidad que los contenidos desarrollados en el secundario.

En sus respuestas emergen también, aunque con un reconocimiento sensiblemente menor, aquellos factores que siendo externos a la voluntad y disposición del estudiante condicionan en alguna medida su desempeño académico, tales como: la 
organización del material de estudio por parte del profesor, las condiciones económicas, las normativas institucionales y organizacionales que regulan el funcionamiento de la facultad y por tanto, su propio comportamiento en el trayecto de la carrera. En cuanto a este último aspecto, aluden a la falta de información pertinente y oportuna, a un régimen de correlativas "que muchas veces hace correr contra el reloj", a los horarios de cursado y a cuestiones en apariencia tan triviales como el desconocer a qué se llama "parciales" en el contexto universitario.

Conforme lo expuesto, resulta clara la importancia atribuida por los estudiantes a la autorregulación, ya que tanto sus respuestas como sus señalamientos enfatizan casi exclusivamente en el desajuste de los procesos de esta naturaleza con relación a las demandas de institución universitaria. Al mismo tiempo, sólo unas pocas consideraciones refieren a carencias de índole cognitiva, refiriendo puntualmente a limitaciones para la comprensión lectora, el estudio basado en el análisis de los textos y el establecimiento de relaciones, y la resolución de exámenes extensos.

En el siguiente apartado, adentrarnos más detenidamente en el examen de las condiciones que mediatizan el estudio y las vivencias del estudiante en la universidad, nos permitirá profundizar estas dificultades que atraviesan en su ambientación a la cultura universitaria, apelando a sus propias palabras.

\section{C) Particularidades del estudio en la universidad con referencia a la escuela}

Este último apartado reúne las apreciaciones y valoraciones de los estudiantes entrevistados acerca de las condiciones de estudio y aprendizaje en la universidad, en relación con el nivel medio. Complementariamente se incluye información provista por el cuestionario, referida a sus señalamientos en algunas de las afirmaciones sobre el modo de estudiar y aprender en la universidad y las principales dificultades que afrontan en la vida estudiantil.

\section{La conquista de la autonomía: "Uno viene con todo prácticamente determinado y de golpe se encuentra con que uno tiene que determinar las cosas".}

El conducirse de modo más autónomo e independiente en el ámbito universitario es una necesidad clave en la valoración de los estudiantes, estrechamente ligada al éxito en el proceso de adecuación a las pautas y condiciones del nuevo nivel. La cuestión de la autonomía en las decisiones distingue cualitativamente la vida universitaria del rol de alumno en la escuela secundaria, y se expresa principalmente en la determinación de asistir regularmente a clases, organizar el tiempo destinado al estudio y ser constante en el esfuerzo. Como condición indispensable para la vida académica satisfactoria se contrapone al control, seguimiento constante y mayor orientación que atribuyen los alumnos a las instituciones y autoridades del nivel medio. Se vincula además con un grado de exigencias mayor y diferente respecto a los requerimientos del secundario. Los estudiantes personalizan las exigencias de la escuela en el acompañamiento de agentes externos como los profesores, los padres y hasta los propios compañeros, pero al transitar la universidad advierten que tales exigencias asumen una naturaleza inherente a ellos mismos, por lo que cabría hablar de una autoexigencia que se traduce en la creciente responsabilidad por uno mismo.

De acuerdo con Casco (2009), este mandato central de la institución universitaria es entendido, de modo general, como la capacidad del ingresante para "arreglárselas solo" en un medio poco estructurante. Las expresiones que siguen reflejan la clara 
conciencia de estos estudiantes respecto del carácter determinante que reviste la conquista de la autonomía de cara a la permanencia en el sistema.

Sí, ya no es más externa, vos te exigís. La exigencia es más tuya, sabes que manejas tus tiempos, tus ganas, te pones tus tiempos y dependes de vos acá. En la escuela existen exigencias, presión y un seguimiento en el estudio que en la universidad no se da, acá se trata del compromiso con los objetivos que uno mismo se propone. Tiene que ver con un cambio en las responsabilidades como estudiante, porque tenemos más exigencias y eso es lo que ayuda a la vez a poder adaptarnos al cambio.

Creo que en la secundaria uno está como más guiado y determinado en todo lo que hay que hacer y te enseñan cómo hacerlo, y en la facultad se ponen en práctica esas estrategias que te enseñaron allá, ya no hay más alguien que te va a decir: 'estudia, ponete las pilas, hace tal cosa', no, sos vos el responsable (...) en la facultad te vas a tener que adaptar a eso digamos porque claro vos sos el que regulas tus tiempos. En la escuela se tiene más la presión de los padres, de los profesores y los preceptores y sus exigencias, todo está ya pautado. En la mayoría de los casos sabes que en los 5 años de la secundaria la vas a tener que terminar sí o sí como sea, y acá se te puede dilatar podes terminar antes como podes terminar después, sos el responsable de acuerdo a las pretensiones y a las metas que tengas en tu vida.

Uno viene con todo ya prácticamente determinado y de golpe se encuentra con que uno tiene que determinar las cosas, entonces primero si te cuesta empezar a... en la escuela está todo marcado vos sabes que si no vas, si pasas las 15 faltas te quedas libre y perdes el año, en la facultad no, o sea vos podes quedarte en tu casa a dormir si queres todo el día, pero después la perdes, quedas libre y te das cuenta de que estás hace mucho tiempo acá y estás haciendo más gastos.

En el curso del nivel medio el alumno se encuentra más guiado y acompañado en el marco de ciertas reglas explícitas y pautas estables, y de orientaciones constantes por parte del entorno y las autoridades que lo contienen. Por el contrario, el joven universitario frecuentemente se revela como un sujeto individual, aislado, solitario y que en consecuencia debe conducir sus asuntos como puede. Al mismo tiempo y paradójicamente, emerge como alguien con poder de decisión y libertad de acción, en el sentido de que 'nadie lo manda', aunque esto implica que en el ámbito universitario todo depende de él mismo (Leite, 2003). Una estudiante lo explica así:

Es mucho más autónomo el estudio universitario, sobre todo el tema de que vos sos responsable del tiempo que te lleve la carrera, de cómo la hagas, de la forma en que la comprendas y de todo. Sos responsable de tu carrera, de haberla terminado rápido y comprensivamente o de que tu carrera la hayas hecho a los saltos y como pudiste digamos mal, mal; cuando no tenías ganas y no querías hacer las cosas. La presión pasa más por algo interno porque sabes que si estudias te va bien. En la secundaria había una presión siempre de ponete las pilas, seguí, no te quedes, hace esto hace lo otro todo el tiempo desde los profesores, los padres o los compañeros... acá sos vos. 
Aún cuando unos pocos alumnos entrevistados reconocen un cierto grado de autonomía durante su desempeño en el nivel medio, la necesidad de aprender a resolver los requerimientos del estudio universitario de forma autónoma es una constante en el discurso de la mayoría. Esto se pone a prueba en cuestiones tan decisivas como la capacidad de organizar el tiempo y regular los esfuerzos en forma adecuada, lo cual a su vez condiciona el grado de cumplimiento de actividades académicas frecuentes como el cursado de materias, la lectura y realización de trabajos, la preparación y el afrontamiento de exámenes. Precisamente, la relevancia de concurrir regularmente a clases es otro de los asuntos comunes entre estos estudiantes. Del total encuestado, sólo uno de ellos señala que frecuentemente no asiste a las clase en las que no se registra la asistencia, en tanto el resto prefiere concurrir de todos modos. La situación de clase les posibilita llevar un seguimiento del desarrollo de las materias, tomar conocimiento de aspectos de interés para los profesores y lograr una mayor comprensión de los textos. Así lo manifiestan algunos:

Voy porque puede decir cualquier cosa sobre el tema que estamos trabajando, sobre horarios o bibliografía y te ayuda, o sea, cualquier información que te den en clase te va a ayudar sí o sí. Por ahí encima dan síntesis espectaculares, por ejemplo al profesor $X$ nunca le falté porque en su materia es impresionante, él da unas síntesis fabulosas para ir a estudiar después. Con él no necesité que mi compañera me ayude a interpretar, fui directamente a sus clases y después fui a la bibliografía.

Se me hace que es muy importante porque es como que vas agarrando confianza con el profesor y te vas sacando más dudas y cuando vas a estudiar te resulta más fácil comprender. Es importante, por ahí te quedas colgado como van demasiado rápido en esas materias cuatrimestrales, y si faltas una clase es como que ya te quedas, por ejemplo en Estadística el primer bimestre sería fui o para el primer parcial fui y entendí bastante, me fue bien y para el segundo ahora empecé a no ir porque tenía un montón de trabajo para Didáctica y estoy re perdida, ahí te das cuenta por ej.

El eficiente manejo del tiempo, el esfuerzo sostenido y la dedicación emergen como las batallas más difíciles que deben librar los estudiantes en su deseo de adaptarse a las exigencias de la nueva modalidad institucional. Dan cuenta de que la posibilidad de resultar victoriosos frente a este desafío les requiere indefectiblemente abandonar hábitos consolidados durante la escuela media, hábitos que por lo general condicionan ampliamente los resultados que obtienen en términos académicos y de afiliación intelectual a la cultura universitaria.

De la contención escolar a la lejanía de los vínculos interpersonales en la facultad: "Vos seguís haciendo la tuya, si queres vas si queres no vas..."

Las relaciones interpersonales se describen principalmente en torno al trato con los profesores y necesariamente con referencia al nivel medio. En la valoración de los estudiantes, tanto la dinámica de las clases como las relaciones menos personales, más discontinuas y circunstanciales que singularizan los vínculos se corresponden con el mayor grado de exigencia que reviste el estudio universitario en comparación con la institución escolar. Sus explicaciones insisten en el papel que asumen profesor y alumno en cada contexto, oponiendo la supervisión y preocupación constante de los 
docentes en la escuela, a la autogestión universitaria y el relativo anonimato que caracteriza los primeros pasos del estudiante en su ambientación a la institución universitaria. Entre las expresiones alusivas a la cuestión, se recogen éstas:

En la universidad bueno, te conocen porque estas participando o directamente fijate yo no curso algunas materias, o sea que los profesores me conocen de los parciales y del final, totalmente neutro podes ser y no va ni viene, vos seguís haciendo la tuya si queres vas si queres no vas cosas así, y es más no te están evaluando te evalúan en el final y tal vez listo entendes, ya está.

Los profesores en la secundaria era como que estaban más encima, acá ya no están más pendientes de vos, somos muchos y al profesor no le interesa si sigo o no sigo, si dejo la materia o si la apruebo... depende de mí. Los profesores saben que si vos dejaste la materia es porque te pareció lo mejor de acuerdo a tu ritmo, a tus tiempos, tu organización y tampoco tienen necesidad, ni la obligación, ni el derecho ni nada de recriminarte. Pasa por vos, por tu responsabilidad y tus decisiones $y$ en ese sentido se nota la autonomía, como que antes era menos lo que podías definir por tu cuenta.

Frente al aislamiento o aparente soledad en que se desarrolla el estudio en la universidad, y dada la impersonalidad acentuada de los vínculos que estrechan sus principales actores; el colegio secundario es percibido como un espacio más familiar y placentero que brinda mayor contención y seguridad al alumno. Este clima afectivo posibilita establecer relaciones más íntimas y de mayor confianza con los docentes, incluso con miras a especular sobre el grado de permisividad o condescendencia frente a determinadas circunstancias. Algunas contribuciones al respecto denotan:

Siempre digo eso, en el secundario como que había una relación más estrecha con los profesores, y uno por ahí bueno no quería rendir, no rindo presento un certificado médico y zafo rindo después, no hago un trabajo práctico capaz no me dicen nada.

En la secundaria era te digo la amistad entre comillas con los profesores, acá extraño la relación que tuve con todos ellos. El trato con los profesores es menos personal en la facultad, a parte fijate en la secundaria éramos 25 o 26 chicos, nos conocíamos todos, hablábamos uno con el otro... acá somos, hay clases que somos más de 90.

Creo que el estudiante esta mucho más cómodo en el nivel medio, ya sea por el acompañamiento o el trato más directo con el profesor, creo eh... los profesores, la ayuda de los preceptores y el compañerismo, que todos...uno está más contenido, todo el mundo te conoce...estabas más cómodo totalmente.

A este respecto, coincidimos con Corral de Zurita (1995) en cuanto a que la principal diferencia entre ambos niveles educativos reside en el hecho de que mientras la escuela media asume la contención de los estudiantes, la universidad les concede y requiere el ejercicio de la autonomía. Como lo sostiene la autora, el nivel medio proporciona una red de sostén mediante un control y seguimiento que involucra la amplia gama de comportamientos dentro del establecimiento, que, en cierta medida, 
se extiende fuera de éste. Como consecuencia, el joven delega en la institución gran parte de la responsabilidad de sus comportamientos. A través de preceptores, profesores e, indirectamente, a través de los padres, la que se ocupa y se preocupa de su rendimiento y su obrar es la escuela. Por el contrario, la institución universitaria se caracteriza por liberalizar este control y entonces, sin transición, el joven se encuentra en un ámbito donde debe empezar a hacerse cargo de su propia formación.

En este sentido, Álvarez Méndez (2003) sostiene que algunos profesores dedicados fervientemente a la tarea de transmitir información sobre contenidos concretos, suelen pasar por alto componentes afectivos, de autoestima, la historia y el contexto propio de los sujetos a los que va dirigida tanta información. Como expresa el autor, el aula no parece un espacio propicio para considerar sentimientos ni experiencias personales, ni los intercambios intersubjetivos de quienes se encuentran y trabajan en ella. Puede que esto ocurra con mayor frecuencia en el ámbito académico abocado a la formación de jóvenes adultos, donde además se reciben masivas poblaciones de estudiantes.

Respecto a la interacción con los pares, hacen referencia a ciertos inconvenientes que plantea establecer nuevas relaciones en una institución desconocida y el fortalecimiento de un buen grupo de trabajo (falta de comunicación entre compañeros, tendencia al aislamiento, experiencias de grupos disfuncionales, etc.). Pese a las dificultades que suscita trabajar en equipo, ya desde el secundario muchos se habituaron a esta dinámica. Quizás por ello, dos tercios de los estudiantes frecuentemente prefieren compartir la tarea con un grupo antes que hacerla individualmente. Relacionarse y aprender a trabajar con otros es percibido por la mayoría como una disposición favorable para los logros académicos satisfactorios. A propósito de la conformación y funcionamiento de los grupos, sus palabras testimonian tanto experiencias positivas, como otras negativas y de mayor inestabilidad:

No, no me costó mucho. Bueno si vine con $J$ que la conozco desde que tengo 7 años, entonces como que había venido con ella y después cada una se fue abriendo y entró $V$ al grupo, después $E \ldots$ a parte dentro de todo soy bastante cerrada, no tengo problema de relacionarme pero tiene que pasar un tiempo también, no me voy a ir a relacionar con cualquiera a la primera. Nosotras somos un grupo y estamos entre nosotras la verdad que no tenemos mucha relación con los demás, recién ahora por ahí vamos al curso y hablamos con aquel o con este, pero sólo en cuanto a trabajo.

Ahora tenes que trabajar sí o sí en grupo, el trabajo es muy difícil, hay poco tiempo y acá en la facultad te hacen exactamente lo mismo que en la escuela. En primer año todos los profesores te pedían grupos, bueno, entonces me tuve que poner en grupo otra vez y si me costó relacionarme en el ámbito de formar grupo, de confiar en ellos para que hagan el trabajo, eso nomás porque después en lo personal no tengo problema y hasta recién nomás encontré gente que se va a poner a hacer, que es trabajadora, es cumplidora y responsable. Encima no podes criticar porque no tienen la culpa, ellos tienen exigencias diferentes, te tenes que apegar a lo que ellos necesitan y quieren, y tu trabajo jes triple! Me costó un montón, un montón me costó... trataba de conseguir alguien que trabaje pero es re difícil, re difícil porque no entran con las ganas de trabajar, con el deber de lo tenes que hacer. Hice grupos con gente de mi edad que salía de la secundaria e ingresaba, y el primer cuatrimestre fue así, el segundo fue peor, terrible. 
Frente al desafío de la autorregulación: "Ese voy a estudiar después, voy a ver después... es como que el después ya no existe más".

Si bien, en su mayoría, asumen el hecho de que conseguirán proseguir la carrera en la medida en que logren dedicarse y manejar sus tiempos de forma eficiente, más de las veces se encuentran en 'aprietos' intentando responder a las demandas académicas "contra el reloj". Por un lado, se dicen conscientes de la necesidad de incrementar el esfuerzo y el tiempo destinado al estudio en la universidad en comparación con el secundario, por otro, se confiesan imposibilitados de llevarlo a la práctica en numerosas circunstancias. Se trata entonces de una asignatura pendiente que mientras que a algunos los angustia, a otros los desborda en su voluntad de cambio. A título de ejemplo se transcriben algunas de sus respuestas:

Tengo semanas que son súper agotadoras, pero súper agotadoras ahora hace como dos semanas que ando a mil entendes, entonces como que no puedo, no estoy ni terminando una cosa y ya estoy con la otra, tengo que estar viendo: "No, a la clase de hoy voy a tener que faltar para terminar lo otro de mañana" cosas así. Termino súper cansada y después tengo, por ejemplo ahora antes de que empiecen los prácticos y parciales de nuevo, esas semanas que estás tan tranqui que otra vez te acostumbras a no hacer nada y por el sólo hecho de decir ya estuve bastante cansada esas tres o cuatro semanas que anduve súper ocupada, así que ahora quiero descansar y decís: "Igual mañana me voy a levantar y voy a estudiar" pero como sabes que en realidad no es una obligación o una presión que tenes, tal vez te dormís toda la mañana. Como que esas semanas estás más en otra cosa, colgada y después otra vez vuelve el tema de estar a las corridas con la facultad...

La constancia para mí es terrible porque me pasa que por ahí estás tan enganchada con una materia, tan pilas quizás porque te están exigiendo con los parciales y el práctico y como que saliste de entregar ese parcial o práctico y decís: "bueno, ahora ya me desligue". Otra vez te perdés totalmente, como por dos semanas no queres ni siquiera abrir eso y cuando te diste cuenta te descolgaste...se necesita ser constante.

En la percepción de muchos de estos jóvenes resulta crucial el progresivo abandono de un hábito comúnmente adquirido en el secundario, donde el estudio asumía un carácter circunstancial con vistas a la superación de instancias concretas de evaluación. Por su experiencia durante el primer año en la facultad, cuyas exigencias son claramente diferentes a las de la escuela, saben que la tendencia a estudiar bajo presión o "a última hora y para el momento" es una práctica perjudicial, no sólo porque no les permite resolver convenientemente los requerimientos de sus profesores, sino también porque conlleva un fuerte sentimiento de frustración e impotencia.

Conforme los datos provistos por el cuestionario, desorganizarse al estudiar para distintas materias en la misma semana, realizar trabajos apremiados por el tiempo, posponer obligaciones académicas más de lo conveniente e improvisar por no cumplir con el modo en que planifican desarrollar sus actividades, son situaciones comunes en la vida de estos jóvenes universitarios. Sólo menos de un tercio casi nunca las atraviesa. Pese al ímpetu de cambio que se manifiesta en algunos casos, respecto a poder generar ajustes en la actuación académica, lo cierto es que al cabo de un año de permanencia en la universidad muchos de ellos mantienen prácticas de estudio 
muy similares a las llevadas a cabo en la escuela secundaria. En el decir de unos estudiantes:

No tendría que pero sí me complica, porque en realidad estoy acá para estudiar y vivo sola y tengo todo el tiempo del mundo, mi vida acá tendría que basarse siempre en eso digo yo, pero no sé... estoy estudiando a veces y no tengo ganas, tengo toda la mañana y no tengo ganas de estudiar sé que está la cama voy y me acuesto o sé que está $A$ voy y la busco. Tengo computadora, estoy sola aburrida agarro pongo música o veo películas, el modo como organizo mi estudio está muy ligado a mi motivación o estoy bajo presión de que tengo que rendir y ahí como sea no existe el mundo y estudio. Si tengo tiempo y estoy sin ganas no estudio pero cuando estoy bajo presión es estudio y estudio. En la escuela era levantarme y preparar en el día o el día antes.

Me pasa eso sí, fijate que trato tipo hoy sé que tengo que estudiar o leer una fotocopia para la semana que viene y capaz la saco y digo: "bueno la voy a leer"... la tengo pero no la leo es como que espero a que llegue dos días antes y ahí sí, cuando ya tengo otra cosa que leer para otra materia se me amontona todo y como puedo me arreglo y leo. La verdad que traté de cambiar eso, pero ya no puedo ya es mi costumbre y no cambió de la escuela. Bajo presión uno está mejor, por lo menos yo.

Si, más cuando tengo que rendir estudio. Mantengo eso de la secundaria, por ahí me doy cuenta de que estoy desocupada o de que tengo un tiempo libre y trato de sentarme, y esto tendría que ponerme a leer y trato, pero generalmente como siempre estamos con prácticos y todo ese tipo de cosas no lo hago. Cuando falta poco para el parcial ahí me pongo a leer o nos juntamos a estudiar...

La aún deficiente autorregulación se advierte en el hecho de que al distribuir inadecuadamente el tiempo y dedicarse al estudio de modo inconstante, estos alumnos atraviesan inevitablemente períodos de intensa actividad en los que procuran responder simultáneamente a requerimientos de variadas materias y profesores. En momentos de menor demanda académica, antes que planificar obligaciones futuras, optan por distenderse y realizar otro tipo de actividades. También la motivación juega un papel clave como otro de los condicionantes comunes a la hora de organizarse.

A pesar de las dificultades que conlleva programar el uso del tiempo, el interés por la planificación de las tareas aparece como un rasgo propio del desempeño académico y raramente presente en el contexto escolar. Sin embargo, muchos reconocen una recurrente distancia entre el modo como pensaron hacer las cosas y la manera en que efectivamente las hacen. La proximidad de las situaciones evaluativas, la presentación de trabajos o la desmotivación los sitúa en el camino de la improvisación, el reajuste de las propias acciones sobre la marcha o el estudio bajo presión. Son varias las consideraciones que dan cuenta de ello:

Si lo arreglamos con el grupo y yo también me organizo. A veces se puede cumplir con eso, pero generalmente se termina haciendo sobre la marcha, como que lo que planificaste nada que ver a lo que te salió entendes. Por ahí yo planifique empezar dos semanas antes y termine en una semana yendo y leyendo un ratito, total sabía que me quedaba toda la otra semana y así, entonces por ahí lo deje más para la 
última semana que ya es mucho tiempo menos y que tenes que estar a las apuradas.

Puede ser que yo acá en mi cabeza planifico sí, en el sentido de estudiar. Por ejemplo mañana hace una semana que vengo planificando que tengo que empezar a estudiar Estadística, digo mañana a la noche antes de... o termino de mirar la novela y estudio hasta las una... pero no, no lo hago. Del dicho al hecho "me falta el hecho".

Por ahí me cuesta ir haciendo constructivo y seguido el estudio de una materia que no me interese, como Estadística que encima me cuesta. No puedo estudiar antes porque no me gusta, no me llama la atención entonces solamente la presión del examen me ayuda a preparar. Si es con mayor intensidad antes de rendir, excepto si me interesa la materia entonces por ahí las leo antes.

En ocasión de un trabajo anterior, cuyo propósito fue examinar las concepciones y prácticas de estudiantes futuros profesores respecto a la evaluación, hemos tenido la oportunidad de constatar la relevancia que reviste la autorregulación al momento de dar cuenta de la actuación académica. Aspectos como el manejo del tiempo, la dedicación y la continuidad en el esfuerzo, el registro de apuntes, la atención y concentración, fueron mencionados recurrentemente por los alumnos, tanto para explicar el éxito y el fracaso académico como para destacar el tipo de estrategias que se deben poner en juego cuando se desea aprender y cuando se pretende aprobar (Silvestri y Corral, 2005). De igual modo, un estudio acerca de las representaciones de ingresantes de ingeniería sobre el ser universitario, reveló las mismas significaciones en las apreciaciones de los estudiantes sobre la importancia de desarrollar el sentido de responsabilidad, esfuerzo y constancia en la organización del tiempo destinado al estudio y a las tareas académicas (Berrino, M. Inés y otros, 2006).

\section{Habilidades estratégicas en la adecuación al contexto: "Vas adquiriendo un historial, un conocimiento y un reconocimiento que es más para rendir".}

Participar en clases, tomar apuntes de las explicaciones de los docentes, consultar diversas fuentes para interpretar el vocabulario disciplinar, leer y estudiar comprensivamente son sólo algunos de los recursos valorados por los estudiantes para regular satisfactoriamente su actividad lectora, para desentrañar la complejidad de los contenidos e implementar modalidades de estudio más ajustadas a las exigencias del nivel superior.

\section{- Participar en clases}

Por sentirse inseguros respecto de sus ideas y reflexiones, la mitad de estos alumnos frecuentemente participa poco durante las clases, situación que también señala experimentar en ocasiones cerca de un tercio de ellos. Durante las entrevistas mencionan aspectos favorables a propósito de esta estrategia, tales como: plantear y despejar inquietudes sobre los contenidos, precisar si la comprensión de los temas sigue un buen curso, enriquecer y ampliar perspectivas a partir de los aportes de los compañeros, lograr que los profesores los conozcan "más de cerca" y dispongan así 
de indicios sobre el modo como van aprendiendo la materia. Pero, consistentemente con sus señalamientos, la mayoría de los entrevistados reconoce que desde el inicio de la carrera han disminuido considerablemente sus intervenciones en las clases.

Algunos explican esta tendencia refiriendo a la disposición del profesor para oírlos, o a las condiciones de un ámbito escolar que propiciaba la participación espontánea en un clima más distendido (en razón de la mayor cercanía y confianza en las relaciones entre pares y docentes). Mientras que en la escuela, el hecho de conocer mejor a los compañeros y profesores los desinhibía al momento de hacerse escuchar, en el aula universitaria reservan sus alocuciones para los espacios de debate o discusión grupal. Unos lo expresan de la siguiente manera:

De los casi 2 años que llevo en la facultad si me tendrían que calificar por participación para atrás. En la escuela sí, porque me sentía en un ambiente más cómodo, nos conocíamos todos, llevábamos mucho tiempo juntos y si uno cometía un error nos reíamos todos pero no se reían de mí sino conmigo digamos y la profesora bien, normal. En cambio, acá uno se equivoca y ese miedo a que los demás se burlen, tengo miedo de que me pase pero porque vi compañeras a las que les pasó.

Hay profesores que tienen muy en cuenta eso, incluso sé de casos en los que cuando van a rendir prácticamente no le preguntan nada porque ya lo conocen, y saben que es una persona que siempre está en el tema que está participando, entonces viene le hacen una pregunta simple y ya está. $Y$ vi casos en los que el profesor no te conoce y empieza, como que quiere ver todo lo que sabes.

Participar en un debate sí porque ya tenía experiencia de la secundaria. Dar ideas propias o refutar o aceptar la idea de otro es muy enriquecedor, y eso también fue una prueba grande el año pasado en los prácticos de Psicología nos dieron un tema para que preparemos un debate, y era un ida y vuelta con los otros compañeros y los profesores de moderadores, así que los debates bien... sirven mucho.

\section{- Registrar apuntes}

Otra de las habilidades deseables para afrontar el estudio, tanto o más importante que la anterior, es la práctica de tomar apuntes. A diferencia del registro literal característico de la escuela, en la facultad se privilegian los apuntes personalizados, es decir, aquellas síntesis en las cuales cada alumno decide qué es meritorio recuperar y cómo hacerlo utilizando diferentes formatos (textos de mayor o menor extensión, prolijidad, orden o secuencia en lo registrado, grado de profundidad y detalle de la información). Para algunos estudiantes, los apuntes constituyen un soporte de estudio clave como complemento de los textos originales propuestos por los profesores. Más precisamente, los definen como elementos "clarificadores" de aquellas cuestiones ambiguas o complejas que suscita la lectura de la bibliografía:

Siempre, siempre hago apuntes. Me parece que cuando los profesores desarrollan temas lo sintetizan en 3 palabras y eso es lo que anoto, después si tengo un oral o un escrito pongo eso y está bien. Me acuerdo que estábamos dando las teorías del consenso y del conflicto y nadie entendía, yo no había estudiado aún, teníamos un final y la profesora dijo: “¿Cómo no van a entender? la teoría del conflicto es tal y tal cosa y la del consenso tal y tal" tomé nota y en el final puse eso y estaba bien 
porque me felicitaron por la capacidad de síntesis, y era tal cual lo que ella había dicho.

Llego, me siento y empieza a hablar la profesora y ya empiezo a anotar todo, si tengo alguna duda le pregunto y voy haciendo una especie de síntesis. Me sirve muchísimo para los parciales cuando tengo que prepararme. Te vas a la bibliografía y no sabes en realidad ni a lo que apunta la materia, o sea, el apunte te ayuda después a entender mejor los textos o las copias que tengas que leer, por lo general te da un encuadre. El apunte me acompaña siempre, o sea está al lado de la fotocopia, de los libros o del material que esté trabajando.

En cambio, para quienes prefieren leer y estudiar de los libros o fotocopias, los apuntes de clase no pasan de ser un "material de consulta circunstancial", cuyo uso no facilita ni modifica mayormente las condiciones de estudio ni la comprensión de los contenidos. La determinación de tomar notas queda supeditada al interés que genera la dinámica de las clases, como lo explican algunos:

Los tengo a mano lo que pasa es que por ahí como te dije no voy mucho a clases, más que nada me baso en mis las fotocopias sería, pero sí por ahí los tomo y me doy cuenta que me sirven, podrían ser como de consulta. O sea, sé que tienen importancia los apuntes porque me pueden aclarar muchas cosas pero no los tomo como base de mi estudio, si tengo los uso también y sino de las fotocopias.

Tampoco le doy mucha importancia a los apuntes, creo que los agarro cuando hay que hacer prácticos y que ahí viste que también sirven bastante para eso. Te diría que si los tengo, porque la mayoría de las veces yo me arreglo con las fotocopias, tomo apuntes sólo cuando me interesó el tema o si la clase estuvo buena.

\section{- Recuperar la palabra del profesor}

Una cuestión estrechamente vinculada con el registro de apuntes refiere a la intencionalidad de recuperar los sentidos privilegiados en la "palabra del profesor". Los apuntes condensan las explicaciones e interpretaciones del docente, constituyendo así una síntesis de los temas que ayuda a contextualizar y delimitar las cuestiones más significativas, aquellas a las que el estudiante sabe es conveniente prestar especial atención para responder a sus demandas y expectativas. Por ello, no es de extrañar que casi la totalidad, con frecuencia interprete mejor los textos mediante las explicaciones y comentarios de sus profesores.

Según cómo los docentes desarrollan y explican los contenidos de la materia en las clases; es posible complementar y ampliar los textos, percibir a cuáles aspectos atribuye mayor relevancia, como así también recoger indicios de lo que podría ser "tema de examen". Incluso, ciertos alumnos reconocen que llegan a estructurar el estudio en torno a dichas cuestiones, como lo expresan sus propias palabras:

Mmm, o sea es una guía para ver cómo vas a tomar el tema o cómo lo vas a leer, porque bueno pensas esto el profesor dijo que no era tan importante y lo dio así muy a simple vista y dijo que no nos basemos tanto en eso, así que le haces una leída rápida, o al contrario tal vez profunda por lo que él dijo. Por ahí hay profesores que arman una síntesis re buena y necesitas leer bien el apunte y con eso es suficiente, después si tenes alguna duda vas a la bibliografía. 
Como te dije hoy, es lo que después piden ellos o vos lo... como que en el examen lo callas diciendo eso que él dijo en clases. Hay una palabra que no me sale ahora pero es eso, es lo que él espera que digas después. Te sirve por ahí para ver qué términos usa él, para mí eso es importante, ver qué términos utiliza o cómo desarrolla el tema, para en un parcial vos ir y que se dé cuenta que fuiste a las clases y estás utilizando los mismos términos que él uso...

\section{- Fortalecer el hábito de la lectura}

En cuanto a la lectura, una representación compartida por casi todos los estudiantes es que a la universidad se viene a leer, y mucho. Entre sus numerosas expresiones alusivas a la intensidad de dicha actividad en la facultad, se recogen éstas:

Cuando vi Corrientes del Pensamiento Contemporáneo no podía creer la cantidad de bibliografía en una materia, me dije ;Guauu, estoy en la Universidad!

Yo cuando empecé la universidad sabía que era mucho más que en la escuela, te venís con la idea pero ves unos apuntes así y decís: ;Wee! ¿Todo esto tengo que estudiar? Nunca he visto tanta bibliografía, muchos contenidos, muchas palabras, muchas cosas...

Acá se basa todo en que te guste leer, porque si a vos no te gusta leer ahí si te va a costar mucho más.

Asimismo, en su mayoría caracterizan el contenido de los textos académicos como complejo y cargado de supuestos e información implícita, lo que origina dificultades en la comprensión y exige una aguda capacidad de interpretación y análisis. Como contrapartida, ponen de relieve el carácter manifiesto o evidente de la información contenida en los textos trabajados en la escuela.

En este sentido, Weibel (2006) sostiene que los textos empleados para enseñar en la facultad derivan de textos científicos y presentan una complejidad significativa para alumnos recientemente egresados del nivel medio, ya que presentan ciertas características discursivas a las que ellos, por lo general, no están habituados. Precisamente, la caracterización que ofrecen los estudiantes acerca del material de estudio empleado en la escuela, da cuenta de la argumentación del autor en tanto refieren a una escasa cantidad de textos, de breve extensión, cuya interpretación no plantea mayores inconvenientes en virtud de su contenido explícito. En cambio, al transitar la universidad deben adaptarse a condiciones muy diferentes en términos de las exigencias y desafíos que les plantea la lectura académica.

Así las cosas, familiarizarse con la especificidad del vocabulario disciplinar es concebida como una necesidad más próxima a las demandas de la educación superior, aunque los estudiantes no la reconocen como una problemática de peso en su afiliación intelectual al nivel. Desde su perspectiva, mientras que en el colegio los profesores dedicaban más tiempo a explicar el sentido o connotación de la terminología utilizada, en la universidad les compete a ellos mismos solucionar este tipo de situaciones pues muchos términos se suponen "ya conocidos". Frente al desconocimiento o incertidumbre respecto de ciertas palabras o conceptos, la mayoría prefiere consultar el diccionario o a los compañeros del grupo de estudio. Quizás por 
las características que asumen los vínculos con los docentes, ya mencionadas con anterioridad, la posibilidad de consultarlos por inquietudes de esta índole es la alternativa que encuentran menos viable.

Por otra parte, dependiendo la particularidad de los textos, los estudiantes desarrollan básicamente dos modalidades de lectura: unos prefieren leer por tramos, detenidamente y releyendo párrafos; otros optan por una primera lectura integral en la que infieren el sentido general del texto para luego, en una segunda lectura, reconocer lo principal de cada párrafo. En ambos casos manifiestan su intención de leer comprensivamente tratando de identificar y destacar las cuestiones centrales, es decir, analizando el contenido y relacionando. Asimismo, casi todos los jóvenes prefieren la lectura individual, y curiosamente cerca de un tercio logra mayor concentración al leer en voz alta. Al referir a los estilos de lectura, algunos especifican una secuencia de operaciones a seguir, e incluso de recursos para optimizar el proceso:

Leo y trato de entender comprensivamente, hago una lectura lenta y pausada pero no me detengo a hacerme preguntas; primero hago una lectura general y después en una segunda lectura saco las ideas principales y agrego esas ideas a mis resúmenes de lo que el profesor explicó a la hora de dar la teoría.

Lo que hago es leer una vez en general para darme cuenta de qué trata el texto, la segunda vez voy marcando con fibrón todo lo importante también me queda bastante extenso pero ya es menos, y en la tercera con lo que marqué hago tipo un cuadro.

Una lectura lenta donde voy haciendo llamaditas o notas al margen, vuelvo a leer párrafo por párrafo lo que no entiendo, saco las ideas principales y en general me siento con el diccionario al lado. Muy pocas veces hago primero una lectura general.

Mi idea supuestamente siempre es que voy a hacer una lectura general y después voy a leer pausadamente, pero nunca llego con tiempo para la lectura pausada, siempre leo en general y trato de sacar las ideas principales de lo que leo.

Especial relevancia revisten las diferencias que estos estudiantes marcan con relación a la complejidad de las actividades de aplicación solicitadas en cada nivel. Sus comentarios en este sentido manifiestan que en la escuela, por lo general, las tareas de comprensión de textos involucraban la utilización de una única fuente y consistían en contestar una guía de preguntas claramente definida, cuyas respuestas se hallaban literalmente expresadas en el contenido del texto. Su resolución no requería entonces más que operaciones de identificación de ideas y transcripción de fragmentos.

Dadas estas condiciones, puede afirmarse que la escasa o nula demanda de elaboración y organización de información por parte del estudiante, lejos está de promover pensamiento crítico, análisis o construcción de conocimientos en forma autónoma y reflexiva. Al examinar el tipo de consignas de lectura más frecuentes en la escuela, Fernández y Carlino (2006) advierten que éstas llevan al estudiante a "desagregar o descomponer" un texto en informaciones puntuales, promoviendo una actividad de mera ubicación o reconocimiento que involucra una comprensión 
superficial y fragmentaria. La identificación y reproducción de la información así planteada, favorecería por un lado la lectura insustancial y, por otro, una redacción que reduce la actividad del alumno a la trascripción. En consonancia con las autoras, Álvarez Méndez (2003) considera que en el entorno escolar el eje de transmisión de información se centra más en las funciones de recepción y aceptación (escuchar, leer, copiar) que en las funciones de producción y creación (hablar, escribir, inventar, analizar, improvisar, criticar, argumentar, valorar).

Nuestros resultados muestran que interpretar consignas o preguntas de exámenes, reconocer lo más significativo de un texto o del discurso del profesor y relacionar nuevos contenidos con los ya estudiados, son algunas de las situaciones que frecuentemente $\mathrm{o}$ en ocasiones, plantean dificultades a más de la mitad de los estudiantes encuestados. Con excepción de unos pocos que refirieron una intensa actividad lectora en ciertas asignaturas escolares y la consecuente adquisición de un buen hábito de lectura, las experiencias de aprendizaje desarrolladas en la escuela no parecen haberlos preparado suficientemente para resolver la complejidad de los textos académicos. Dicha complejidad la perciben tanto en el mayor volumen de bibliografía que deben aprender a manejar para cumplir con las lecturas requeridas, como en el tipo de consignas de trabajo y actividades que proponen los docentes para analizar e interpretar textos científicos de distintas disciplinas.

\section{- Estudiar para comprender}

Ahora bien, atendiendo a cuestiones de índole más específicamente cognitiva, encontramos que las experiencias durante el primer año alertan al estudiante sobre la necesidad de modificar y redefinir sus hábitos de estudio, para lograr resultados académicos satisfactorios que le permitan avanzar en la carrera. Aparece con fuerza una representación común acerca de la necesidad de reemplazar progresivamente el estudio de memoria, habitual en la escuela media, por un estudio reflexivo, caracterizado por establecer relaciones y el esfuerzo analítico. En la interpretación de estos alumnos, estudiar pareciera adquirir connotaciones diferentes y hasta contrapuestas según las exigencias del ámbito en que se realiza. Mientras que en la escuela se prioriza un estudio más repetitivo al servicio de la retención y reproducción de información, en la universidad el sentido y los propósitos del estudio se vinculan además con la posibilidad de comprender, interpretar y pensar a partir de aquello que se lee. Sus expresiones al respecto lo explicitan del siguiente modo:

Veo que los profesores acá en la facultad lo que buscan es que vos comprendas, entiendas, analices, relaciones y en el secundario para nada. En el secundario era que vos estudies prácticamente memorístico era lo que buscaban, que aprendas de memoria si después te servía o no más adelante capaz que a ellos no les interesaba. Entonces para mí el secundario se baso en memorizar lo que me daban y en la facultad en comprender lo que tengo que estudiar, hay excepciones pero en general es eso, para mí la facultad es eso, comprender y relacionarlo siempre con todo lo que voy aprendiendo, acá estudio relacionando.

Mi forma de estudiar en la secundaria siempre fue de manera repetitiva, memorística. Si estudias de memoria acá te va a costar mucho porque te exigen la relación entre la teoría y la realidad educativa, hay mucho material y tenes que relacionar siempre. He visto personas que están hace años en la facultad y justamente les lleva muchos años porque todavía no saben cómo estudiar, a veces se ponen a mirar un material y leen, y leen y leen pero están memorizando todo $y$ 
les cuesta porque a veces olvidan una palabra y al rendir eso les mato por completo el examen. El estudio universitario pasa por la interpretación ¿entendes?

No sorprende el hecho de que aún en la universidad algunos recurran al estudio memorístico para fijar y retener conceptos medulares o clasificaciones en las distintas materias, ya que aprender supone la complementación entre procesos de aprendizaje asociativo y procesos constructivos (Pozo, 2007), entre memorizar y atribuir significado en forma activa. Para poco más de dos tercios de los estudiantes, el estudio de memoria resulta también una alternativa deseable frente al desinterés por los contenidos o la incomprensión de los mismos. Precisamente, el repaso consistente en repetir una y otra vez la información, constituye una estrategia asociativa eficaz cuando los materiales de aprendizaje carecen de significado para el sujeto (Pozo, 1990). En su propio discurso:

Estudio de memoria las cosas que no me gustan, que no entiendo o no le encuentro sentido, entonces digo bueno la única solución es que lo estudio de memoria. Bueno si conceptos sí, algunas cosas que tengas que acordarte específicamente, algunos postulados o clasificaciones puede ser.

Hay conceptos que bueno, resignada digo a veces que hay cosas que no me gustan, que no las entiendo y bueno de memoria me las aprendo y voy y me mando, cuando estudio de memoria es porque no entiendo. En realidad no la dejé... a la memoria.

Acá lo único que estudio de memoria son los conceptos, que tenes que saberlos de memoria para algunos profesores, pero términos o conceptos cortos... no podes estudiar de memoria porque es mucho (...) Didáctica ahora me cuesta también porque algunos textos tienen ideas claves que tenes que estudiar de memoria porque a veces no llegas a comprender a tiempo para el parcial.

De acuerdo con Pozo, en su interpretación de las conceptualizaciones de Pinillos, cuando la situación de aprendizaje se torna adversa, porque no se entiende qué debe aprenderse, porque no despierta interés o porque no se dispone del tiempo necesario para aprenderlo, se recurre a procesos de aprendizaje asociativo, más primitivos y menos vulnerables.

\section{- Interpretar las nuevas exigencias}

La necesidad de realizar ajustes en las modalidades de estudio que han desarrollado en la escuela media, responde muchas veces a una clara captación por parte de los estudiantes respecto de un notable cambio en el tipo de requerimientos que les plantea la universidad, tal como lo sugieren en sus referencias al ámbito escolar:

Es más, mucho más exigente y tenes que adaptarte. En el tema de los parciales, de los prácticos uno se da cuenta también, por ahí en la secundaria vos no terminabas un práctico que no era ni la mitad de lo que son ahora en la facultad, ibas y el profesor te entendía "bueno, mira...". Acá es distinto los profesores ocupan su lugar de profesores, vos sos el alumno y tenes que entregar el trabajo cuando te dicen. 
No son permisivos, o sea, no te dejan pasar: 'Cometiste un error, bueno te dejo pasar'. No, ellos rescatan el error, piden autocrítica. En la escuela si son más permisivos.

Fue un cambio brusco en cuanto a los materiales a analizar que te daban ellos, o sea, de un dictado general que te llevaba dos hojas en la secundaria o un librito que te duraba todo el año eh... a venir acá y encontrarte con un libro más grande que el que te duraba todo el año en la escuela, si acá te duraba cuatro meses ya es muchísimo. O sea, te demanda más lectura, más dedicación, más responsabilidad de uno mismo y en ese sentido si fue muy brusco.

Tengo dos hermanas que están por salir de $5^{\text {to }}$ y les digo que la facultad es muy exigente; es mucha lectura y no va a ser como en la escuela que estudiaban uno o dos días y listo, sino que se tienen que ir preparando continuamente, tienen que relacionarse con la gente, aprender a hablar que es lo que a la mayoría nos hace falta, y que ahora ya no estás entre maestros y profesores, sino que ahora ya tiene que ser como algo más en grupo, ya nada es parecido al secundario le digo yo... Acostumbrarse a hablar con la gente, empezar a desenvolverse ellas mismas por su cuenta, ya no dependiendo de los demás sino decidir ellas, tener hábitos de estudio...

\section{- Aprender a rendir exámenes}

Las estrategias para el examen ocupan un lugar central en el imaginario de estos estudiantes, en relación con los ajustes necesarios para adaptarse a las condiciones de la nueva modalidad institucional.

Mientras que la mitad de los alumnos indica estudiar sólo para rendir, la otra mitad señala que casi nunca organiza de ese modo el estudio en la universidad. En el transcurso de las entrevistas, al referir a "cuándo" estudiaban durante la escuela secundaria, muchos coinciden en que lo hacían pocos días $u$ horas antes de las instancias concretas de evaluación. Luego de un tiempo transcurrido en la universidad, también la mayoría percibe la inconveniencia de mantener el estudio a último momento, por lo cual algunos de ellos dan indicios de trabajar para modificar esta conducta, aún cuando intensifiquen el estudio en proximidad al momento del examen. Así lo indican en los siguientes extractos de las entrevistas:

Cambió bastante. Creo que cambia desde el momento en que los profesores te dicen: "hay tantas fotocopias ahí abajo, saquen" y tenes que empezar porque o sino no llegas, necesito bastante tiempo para interpretar bien, aunque el estudio si es más intenso, más profundo cerca de los exámenes.

Mi forma de estudiar cambió principalmente en el tiempo de estudio. Ahora le dedico mucho más tiempo que en la escuela. En la secundaria me sentaba una hora nomás y listo, acá me tengo que sentar unas cuantas horas, pausa por pausa, replanteándome, leyendo, estudio mucho tiempo antes.

En la facultad a la noche y le agregue lo del estudio a la mañana, cuando tengo tiempo siempre a la mañana, necesito estudiar más tiempo porque si no, no llego. En la escuela estudiaba más cuando había pruebas, y ahora por ahí me cuesta ir haciendo constructivo y seguido el estudio de una materia que no me interese. 
Sociología o Psicología a lo mejor porque me gustan más, las voy siguiendo un poco más pero materias como Estadística que encima me cuesta no puedo estudiar antes, no me gusta, no me llama la atención entonces solamente la presión del examen me ayuda a preparar... y es con mayor intensidad antes de rendir sí.

Otros, en cambio, persisten en el hábito de estudiar para rendir, pese a la clara conciencia de que perjudica en buena medida su desempeño e incluso su bienestar. Quizás, la iniciativa de cambio se ve obstaculizada en algunos casos por el hecho de que "funciona" en términos de los resultados obtenidos. Expresan en este sentido:

No, no cambió. No tengo constancia y me di cuenta desde que vine acá que mi sentido de la responsabilidad pasa por el hecho de decir "no cumplí, no fui responsable en todo este tiempo pero yo sé que en estos tres días puedo", por más que termine súper estresada entonces es como que funciono mejor bajo presión, a mi manera cumplo. Se me hace que no lo cambio porque hasta ahora me funciona en cuanto a resultados obviamente (...) yo sé que tal vez estudiando una mañana antes me queda muchísimo más y tengo más frescas las cosas, y voy las relaciono mejor que estar estudiando mucho tiempo antes. Llegado el momento en esos dos días antes, porque me conozco, tengo memoria a corto plazo, rindo mejor bajo presión o lo que sea, pero estudio una mañana antes del parcial, voy y salgo bien.

Acá también estudio para rendir eso es lo malo que hago, insisto en que me falta el hábito. Sería más fácil que haga algo gradual para que "Ah, sí me acuerdo esto ya lo vi..." y repasar en lugar de empezar a fijar.

El oficio de alumno, especialmente en el nivel superior, se construye en torno al aprendizaje de estrategias adaptativas para rendir o ser evaluado. Éstas aluden a las técnicas y procedimientos utilizados para preparar exámenes y al modo como los alumnos abordan, revisan y disponen los materiales con miras a estas situaciones.

Mediante sucesivas experiencias propias y ajenas, el estudiante va aprendiendo a rendir y configura un saber que le permite poner en juego estrategias para sobrellevar el clima de tensión imperante en las evaluaciones y ejercer algún control sobre el desenlace de las mismas. Concretamente, los estudiantes mencionan las siguientes estrategias para el examen: intensificar el estudio en las fechas próximas a los exámenes; profundizar la lectura de temas que el docente no ha podido desarrollar cabalmente en las clases y que no ha evaluado aún; coordinar el discurso y ensayar el examen con el grupo de estudio; indagar los resultados obtenidos por compañeros o grupos que ya han rendido para proyectar sus posibilidades en función del aparente 'nivel de dificultad de la mesa'; consultar a quienes ya han rendido sobre el tipo de preguntas o cuestiones requeridas; y averiguar con otros alumnos acerca de las cualidades personales de sus futuros profesores, como así también de la enseñanza y evaluación que éstos desarrollan.

En esta presentación nos ocupamos de sólo dos de estas estrategias, dada su marcada presencia en el relato de los estudiantes. La primera consiste en pensar las posibles preguntas o tópicos que podrían indagar los profesores mientras preparan los exámenes, dos tercios de los estudiantes señalan utilizarla frecuentemente, en tanto el resto indica su uso ocasional. Anticipar aquello que puede pedir el profesor les permite profundizar el estudio en torno a esos asuntos, los cuales más de las veces constituyen las cuestiones obvias que todo estudiante debería saber si desea aprobar. 
Reconocen también la existencia de perspectivas de análisis propias de la carrera y de núcleos conceptuales en las diferentes disciplinas, cuya centralidad es destacada por los profesores durante las clases y recogida en los apuntes de los alumnos. Afirmaciones al respecto son las que siguen:

Hay conceptos muy obvios que te preguntan o son preguntas que te pueden llegar a hacer, también en la mayoría de las materias hay determinadas preguntas que son tan obvias y te pueden llegar a salvar o a matar en un final (...) como con qué tipo de aprendizaje, paradigma o escuela relacionas algo que dijiste sobre el contenido de la materia. Son preguntas bien amplias que son re propias de tu carrera y que las tenes que saber, como que esas cosas están presentes siempre. Cuando recién vine me costaba ver cómo se relacionan esas cosas, ahora ya lo relacione y lo re mil domino.

Ellos te van diciendo en cada clase qué es lo importante, o sea, te van tirando indicios depende también del profesor. Algunos son accesibles y te van tirando indicios de lo que podrían llegar a preguntar, de lo que les interesa, de lo que es importante y lo que no, o lo que hay que saber para fundamentar ciertas cosas... de ahí ya vas sacando, esto va a tomar y esto no en el examen. Si no existen esos indicios sí, agarro el texto y "esto creo que es lo más importante, esto va a preguntar" y así...

La segunda estrategia considerada refiere a la posibilidad de consultar a compañeros que ya han rendido sobre aspectos relativos a la situación de examen. Encontramos dos posiciones diferentes: quienes apuestan a los beneficios de esta estrategia y quienes prefieren no utilizarla. Los primeros deciden implementarla porque les permite indagar sobre el ánimo o disposición del docente, el clima de la mesa y los temas o interrogantes mayormente planteados. Lo argumentan del siguiente modo:

Sí, siempre que tenemos que rendir por ejemplo así un oral, pregunto a los grupos que les tomó o sobre el tipo de preguntas que les hicieron digamos, porque siempre algunas preguntas se generalizan al grupo y trato de saber cuáles son.

Lo hice desde siempre eso de preguntar cómo está el profesor para rendir, y lo sigo haciendo y capaz lo siga haciendo hasta que termine la carrera. Sí yo sí pregunto, para saber que me espera.

Sí eso sí, al estar esperando que te llame el profesor al que va saliendo le vas viendo la cara y preguntando cómo está la mesa... no me genera nervios. Consulto porque me dan información de la profesora, de cómo encarar la situación de examen.

En el caso de los últimos, manifiestan no averiguar acerca del examen por temor a que el intercambio y la información recibida generen confusión acerca de lo estudiado, o simplemente para evitar acrecentar los nervios característicos de estas situaciones. Ciertos comentarios ilustran dicha postura:

Trato de no preguntar lo que pregunta el profesor cuando estamos rindiendo porque me pierde todo. Si porque a veces te empiezan a decir: "Me preguntó tal cosa y yo le dije..." y ahí vos decís: "No, yo eso no pensé" o qué sé yo... "yo no hubiera dicho eso", entonces tengo que tratar de acordarme lo que él dijo y veo si sustituye o no 
lo que yo tenía pensado decir en el caso de que me pregunte eso, entonces más vale me quedo nomás así y después hablo con el profesor en todo caso...

No, yo no puedo, generalmente no pregunto que le tomaron. Yo estudié hasta... ponele que el examen es ahora a las 4 de la tarde, no sé a las 2.30 de la tarde dije "ya no puedo más" y lo que no aprendí hasta ahora listo, yo conozco mis tiempos y sé que a último momento listo, se terminó... entonces agarro me empiezo a bañar, hago cosas, nos vamos a la facultad. Llegamos, y la típica situación de los finales de pasillos con miles de chicos sentados leyendo, ese momento antes a mí me pone totalmente histérica, no puedo me voy y me siento lejos y espero a que me llamen.

Prácticas de esta índole se hallan fuertemente motivadas por la intencionalidad de lograr resultados satisfactorios en las evaluaciones y, por lo tanto, en general se orientan a organizar la actividad del estudio sobre la base de tácticas dirigidas a adecuar la conducta a las demandas y expectativas del docente y su enseñanza.

Ciertamente, en la necesidad de aprender a ser estudiante los profesores juegan un papel clave pues emergen como los mediadores de la institución, como el rostro visible que encarna y activa sus regulaciones y exigencias no siempre advertidas por los alumnos, aunque si pueden reconocer diferentes estilos y modalidades de los docentes para actuar conforme a ello (Leite, 2003). Las apreciaciones sobre la conveniencia de corresponder a las expectativas e intereses del docente, son más que elocuentes:

Sí, claro se aprende eh, se me hace que uno pierde un poco el miedo ese a rendir a medida que vas adquiriendo un historial y vas conociendo a los profesores, a lo que ellos apuntan o lo que quieren... entonces vamos estudiando para ellos y para su materia. Vas adquiriendo un historial, un conocimiento que es más para rendir, vas conociendo distintos tipos de profesores y sus formas de evaluación y te vas adaptando a eso, más en Ciencias de la Educación hay una variedad inmensa.

Sí se aprende, eso a mí me pasa por ejemplo en clases. Más allá de lo que sabe que puede tomar el profesor en el examen, uno puede ver cómo él se maneja en clases, cómo piensa, qué le interesa... de ahí yo veo qué es lo que a él le gustaría que yo vaya y diga en el examen final, y trato de manejarme con lo que él espera. Sé que hay profesores que pretenden que vos seas crítico o que reflexiones, y otros que vos uses los términos que requiere la materia y yo me baso en eso. Sé que hay materias como (...) donde tenes que ser crítico, relacionar y reflexionar todo, y otras que es ir y si te hacen una pregunta decir lo que vos sabes digamos, eso lo tengo en cuenta.

Tras la presencia regular en clases, el intercambio con pares y docentes y aún las experiencias de evaluación poco afortunadas, el estudiante se vuelve más idóneo en la preparación de los exámenes lo cual supone, entre otras varias habilidades, calcular mejor los tiempos de estudio y desplegar estrategias para controlar en alguna medida la voluntad del profesor. Si asumimos con Álvarez Méndez (2001) que los exámenes deben estar al servicio del aprendizaje, de la enseñanza y del curriculum y, antes que todo, del sujeto que aprende, resulta cuanto menos preocupante reconocer indicios de 
una interpretación tradicional de la evaluación en la que el profesor ha venido desempeñando un papel decisivo, además de decisorio, de un modo unidireccional.

Según el autor, cuando el examen es puesto al servicio de la medición o calificación de la información transmitida que el alumno puede reproducir linealmente, no es un momento propicio para la duda, el equívoco, la confusión o incluso la distracción o ignorancia. El tiempo del examen es tiempo sólo de expresar verdades absolutas y concluyentes, que no dan lugar a réplica. Así, quien aprende lleva la lección bien sabida, lo que importa en esa situación es dar con las claves que aseguren el éxito, que no siempre se identifica con el saber reflexivo. Se trata de la acción estratégica que garantiza el éxito, como contraria a la acción comunicativa, que persigue el entendimiento y la comprensión (Habermas, 1983, en Álvarez Méndez, Op. cit.).

\section{Conclusiones}

De modo general, los datos sugieren un notable incremento en la frecuencia de uso de las estrategias de aprendizaje desde la llegada a la universidad. Con algunas excepciones como la repetición del contenido en voz alta y el resumen, los diferentes tipos de estrategias cognitivas revelan un uso frecuente por parte de la mayoría de los estudiantes, en comparación con su desarrollo en la escuela media. Aunque se observan variaciones en la frecuencia de uso indicada para cada una de las estrategias metacognitivas examinadas, todas ellas se emplean mayormente en la facultad. Ahora bien, poner en juego procesos de autorregulación de la conducta pareciera ser lo propio de los requerimientos en el ámbito académico. Las diferencias más acentuadas respecto de la utilización de estrategias en cada nivel educativo corresponden a este grupo, siendo señaladas como de uso habitual por la mayor parte de los alumnos encuestados.

Su fuerte presencia en la perspectiva de los estudiantes puede comprenderse, si asumimos que tal como sostienen los autores, se orientan a crear el mejor clima posible y las condiciones óptimas para el despliegue de la cognición y la metacognición. Resulta bastante claro que la eficacia en el manejo de este tipo de estrategias constituye una condición necesaria, aunque no suficiente, para el logro de aprendizajes y resultados académicos satisfactorios en el curso de la vida universitaria. Por tratarse de estudiantes que atraviesan un período de ambientación en una nueva cultura institucional a la que desean pertenecer, es cuando menos entendible su mayor preocupación por captar la lógica y la dinámica de los aprendizajes en ese contexto con miras a ajustar cuestiones de índole motivacional y volitiva en las rutinas de estudio características del nivel escolar previo. Estos ajustes condicionan ampliamente tanto la calidad de las estrategias y habilidades de pensamiento que puedan aprender a desarrollar, como el grado de reflexión y regulación que impliquen en estos procesos.

En el marco de una investigación realizada en el año 1994 con ingresantes de distintas unidades académicas de nuestra universidad, se examinó la transición nivel medio/universidad desde las razones privilegiadas para la elección de la carrera y la perspectiva del cambio de modalidad institucional y los procesos de adaptación a este cambio que realizan los estudiantes. Para esta última cuestión se consideraron tres dimensiones: el cambio en la organización y normativa, el cambio en la modalidad de los aprendizajes y el cambio en los estilos de relaciones. Pese al tiempo transcurrido, los énfasis y significaciones de nuestros hallazgos coinciden ampliamente con los informados por Corral de Zurita (1995) en este trabajo. Las similitudes más importantes refieren a la valoración de una clara distancia entre la seguridad que ofrece el secundario, dado el apoyo y orientación continua, frente a la incertidumbre o 
inseguridad del nuevo escenario generada por el mayor grado de autonomía que la universidad demanda. Además, las coincidencias refieren también a los hábitos y pautas de estudio que ponen en juego en la facultad, por ejemplo la asistencia a clases aún en aquellas materias cuyo cursado no es obligatorio y el registro de apuntes. Conforme los resultados obtenidos por Corral de Zurita, pese a la proximidad de los exámenes en la universidad, el tiempo dedicado al estudio es extremadamente escaso, situación que la mayoría mantiene desde la escuela media. Si bien los estudiantes que hemos entrevistado manifiestan dedicar mayor cantidad de tiempo al estudio y a las actividades académicas en comparación con la escuela, lo cierto es que una lectura general de los señalamientos y apreciaciones da cuenta de que esta conducta tampoco ha sido modificada sustancialmente, de allí que sus principales dificultades se relacionen con el manejo del tiempo y la regulación del esfuerzo.

Por otra parte, un punto de interés concierne al desarrollo de estrategias de metacognición para regular la lectura académica. Una interpretación posible sugiere que la transición al nivel superior sitúa a la mayoría de los estudiantes en la intención de revisar sus estrategias y empezar a "leer de otro modo", pudiendo referirnos entonces a una práctica progresiva de supervisar la comprensión en la lectura. Ésta permitiría al alumno no sólo apreciar en qué medida entiende lo que lee sino también en qué sentido lo entiende; además de posibilitar la identificación de dificultades para interpretar el contenido de los textos, lo cual es imprescindible para pensar cómo podrían resolverlas o contrarrestar sus efectos en la comprensión lectora.

El primer año universitario, en tanto período de transición a un nuevo nivel, es un tiempo de extrañamiento y afiliación para el estudiante, quien intenta desentrañar y aprehender las claves de un universo institucional hasta entonces desconocido, a fin de "hacerlo propio" y permanecer en él. El entorno académico contextualiza y matiza el aprendizaje desde condiciones y exigencias diferentes y en principio, ajenas al estudiante, lo cual explica la marcada significatividad que conceden a la adecuada autorregulación como conquista ineludible para el desarrollo de ciertos procesos cognitivos. En perspectiva de estos alumnos, el desempeño exitoso está asegurado fundamentalmente por el hecho de generar las mejores condiciones posibles para que se produzcan los aprendizajes, antes que por el tipo de cognición que dichos aprendizajes involucran.

De cara a los requerimientos de la modalidad universitaria la percepción común sobre las dificultades más importantes pone de manifiesto que a pesar de haber captado en buena medida lo necesario para el éxito en el nivel superior, muchos de estos estudiantes no han logrado producir ajustes permanentes que garanticen el ejercicio de la tan ansiada autonomía en el estudio. Especialmente en cuestiones referidas a la autorregulación de los aprendizajes, en la universidad aún prevalecen prácticas poco eficientes y hasta contraproducentes para afrontar los desafíos del ámbito académico. Puede inferirse una difícil ruptura con la matriz de estudio y aprendizaje que han constituido durante el nivel medio, matriz que el estudiante desarrolló en estrecha interrelación con otros actores cuya presencia debe aprender a sustituir en la universidad por un protagonismo y compromiso propio, en tanto se percibe como el principal "hacedor de su futuro profesional".

Por lo expuesto, es de tener en cuenta que si bien estos resultados sugieren una clara interpretación por parte de los estudiantes respecto de las exigencias que es necesario cumplimentar para sobrellevar el estudio en el nivel superior, no necesariamente dan cuenta de cambios efectivamente logrados en lo que refiere al real despliegue de sus estrategias. Antes bien, pueden significarse en términos de progresivas adecuaciones para responder a las demandas y requerimientos de diversa 
índole, implicadas en las experiencias de enseñanza y aprendizaje que les propone la universidad.

\section{Bibliografía}

Álvarez Méndez, J. M. (2003) La evaluación a examen. Buenos Aires, Miño y Dávila.

Beltrán, J. (1998) Procesos, estrategias y técnicas de aprendizaje. Madrid, Síntesis.

Berrino, M. I. y otros (2006) "Representaciones de los ingresantes a ingeniería sobre el ser universitario" Memorias de las XIII Jornadas de Investigación y Segundo Encuentro de Investigadores en Psicología del MERCOSUR. UBA, Tomo I, pp. 157158.

Casco, M. (2009) "Afiliación intelectual y prácticas comunicativas de los ingresantes a la universidad". Co-herencia, vol. 6, núm.11, Medellín, Colombia, pp. 233 -260.

Corral de Zurita, N. (1995) "La transición nivel medio-universidad. Encuesta a ingresantes: elección y cambio". En página de publicaciones de la universidad: <http://www.unne.edu.ar/web/publicaciones/index/htm> [Consulta: nov. 2008].

Corral de Zurita, N. (1996) "El Primer Año Universitario, variables Académicas y Extraacadémicas asociadas al abandono, la permanencia y el rendimiento académico" En Revista Nordeste, $2^{d a}$ Época. Serie Investigación y Ensayos, núm.3, Universidad Nacional del Nordeste, pp. 121-142.

Coulon, A. (1995) Etnometodología y educación. Barcelona, Paidós.

Gargallo López, B. (1995) "Estrategias de aprendizaje. Estado de la cuestión. Propuestas para la intervención educativa". Teor. Educ., núm. 7, Ed. Universidad de Salamanca, pp. 53-75.

Fernández, G. y Carlino, P. (2006) Leer y escribir en la escuela Media y en la universidad. Diferencias percibidas por ingresantes a la Facultad de Ciencias Humanas de la UNCPBA. Memorias de las XIII Jornadas de Investigación y Segundo Encuentro de Investigadores del MERCOSUR, UBA. Tomo I, pp. 227-229.

González, M. C. y Tourón, J. (1992) Autoconcepto y rendimiento académico. Sus implicaciones en la motivación y en la autorregulación del aprendizaje. Pamplona, EUNSA.

Leite, A. (2003) "De que se trata el aprendizaje en la universidad. Una mirada desde los estudiantes". Revista Nordeste, $2^{\text {da }}$ Época. Serie Investigación y Ensayos, núm. 19, Universidad Nacional del Nordeste, pp. 93-100.

Monereo, C. (Coord.) (2006). Estrategias de enseñanza y aprendizaje. Formación del profesorado y aplicación a la escuela. Barcelona, Graó.

Perrenoud, P. (1996) La Construcción del éxito y del fracaso escolar. Madrid, Morata.

Pozo, J.I. (1990) “Estrategias de aprendizaje”, en COLL, C., Palacios, J. y Marchesi, A. (Comp.) Desarrollo psicológico y educación, II. Psicología de la Educación. Madrid, Alianza.

Pozo, J.I. (2007) Aprendices y maestros. La nueva cultura del aprendizaje. Madrid, Alianza.

Silvestri, L. y Corral, N. (2005) "Representaciones de los estudiantes acerca del éxito y el fracaso en situaciones de evaluación". Memorias de las XII Jornadas de 
Investigación y Primer Encuentro de Investigadores del MERCOSUR. UBA, Tomo I, pp. 305-307.

Teobaldo, M. y Melgar, S. (2009) “Competencias en la comprensión lectora y producción escrita. Alumnos de Institutos Superiores de Formación Docente: dificultades de los estudiantes de 1er. Año". Informes de Investigación y Estadística del Ministerio de Educación del GCBA.

Valle Arias, A., Barca Lozano, A., González Cabanach, R. y Núñez Pérez, J. C. (1999) "Las estrategias de aprendizaje. Revisión teórica y conceptual". Revista Latinoamericana de Psicología, vol. 31, núm.3, pp. 425 -461.

Weibel, E. (2006) "Lectura y escritura en el contexto académico". Actas II Encuentro Nacional del Ingreso Universitario, en CD-ROOM. Universidad Autónoma de Entre Ríos y Universidad Nacional de Entre Ríos, Argentina.

Weinstein, C. y Mayer, R. (1983) "The teaching of learning strategies". Innovation Abstracts, vol.5, núm.32, Texas, National Institute for Staff and Organizational Development, pp. 1-4. 